\title{
Probiotics, beyond gastrointestinal health
}

\section{Letter to Editor}

The description of the intestinal microbiota is the second event that has shaken the current world of medicine after the discovery of penicillin as an antimicrobial therapeutic agent. Their virtues go beyond just the biosynthesis of trace elements necessary for sustaining the organism which they are colonizing, it is a not only metabolic and immunological barrier as it by the characteristics of the same that it generates an impact on later life adult. Alterations like dysbiosis generate such weight that have been directly associated with chronic, metabolic, inflammatory non-infectious diseases, and affective disorders of the individual. ${ }^{1}$ That is the reason for the current boom in the study of those who help proper maintenance of it, probiotics. The rational use of these, adjunctive tool for various disorders, not only generated an impact according to the nature of its components, but also by environmental changes and due to their antigenic characteristics, signaling for maintenance of the digestive system as the system with better immune performance. Five decades ago might seem implausible therapeutic use of probiotics, gaining scientific interest only in the early 90 's.

The intestinal microbiota comprises $10^{12}-10^{14}$ microorganisms in full its weight is calculated together is greater than the adult brain $(2 \mathrm{~kg}$ equilibrium operating immune and metabolic pathways. ${ }^{2}$ Priority is important to maintain gastrointestinal health through the pursuit of this balance, much depends on lifestyle, diet, intake of alcohol, artificial colors; at best, in children, the path of birth, feeding based on breast milk and weaning time and quality. ${ }^{3}$ Dysbiosis has been associated with multiple diseases. It is the current race for the mastery of this topic, research not only with individual strains but with multistrain are being made. We must understand that there are no better strains than others, learn to use probiotics rationally in the same way that antibiotics since each of them are used particularly not only to help resolve the various pathologies described, but for prevention. Reaching mastery can take more decades of study and, have no doubt that someday find the way and changing path and paradigm of medicine, we find in the probiotics rather than in antibiotics's what we have been trying to find or maybe we will find that answer in the balance of employment of both. There is still much to explore and it is our curiosity that has led us to reach the knowledge this investigation has brought us. So, dear editor, I wish that we may reach a grade of knowledge that allows us to modify clinical criteria in al specialties to avoid the belief that the "powders," as some clinicians call them, are
Volume 4 Issue 5 - 2018

\author{
Guillermo Francisco Rosales Magallanes,' \\ Eduardo Daniel Becerra Cardenas ${ }^{2}$ \\ 'Pediatric Infectologist, Head of Infectology Service Hospital \\ ISSSTECALI Mexicali, Mexico \\ ${ }^{2}$ Xochicalco Calmecac University, México
}

Correspondence: Guillermo Francisco Rosales Magallanes, Pediatric Infectologist, Head of Infectology Service Hospital ISSSTECALI Mexicali, President of the subcommittee for prevention and control of nosocomial infections, Member of Mexican Association of Pediatrics, Member of directive board of CPBC, Member of Mexican Association of Infectology and Clinical Microbiology A.C., Member of Drug Resistant Tuberculosis State Committee, Mexican Certification Council in Pediatrics No. 14499 (2015-2019), Mexican Certification Council of Infectious Diseases. No. I 102 (2016-202 I, Brindisi I40I Gran Venecia Mexicali Baja California, Mexico, Tel 6865522278. 686|422062,Email dr_gmagal76@hotmail.com

Received: August 18, 2018 | Published: September 17, 2018

not only placebos, but it is in them that secret and solution to many ills may be found.

\section{Acknowledgments}

None.

\section{Conflicts of interest}

The author declares there are no conflicts of interest.

\section{References}

1. Grochowska M. The gut microbiota in neuropsychiatric disorders. Acta Neurobiol Exp (Wars). 2018;78(2):69-81.

2. Dave M, Higgins PD, Middha S, et al. The human gut microbiome: current knowledge, challenges, and future directions. Transl Res. 2012;160(4):246-257.

3. Cabrera-Rubio R, Collado MC, Laitinen K, et al. The human milk microbiome changes over lactation and is shaped by maternal weight and mode of delivery. Am J Clin Nutr. 2012;96(3):544-551. 